\title{
ARTIGO
}

\section{SISTEMA AUTOMATIZADO PARA REDUÇÃO DE PERDAS ASSOCIADAS AO PROCESSO DE REFRIGERAÇÃO DO LEITE EM PEQUENAS PROPRIEDADES ${ }^{1}$}

\author{
Gabriel Ramos Teixeira \\ Gustavo Lobato Campos
}

\begin{abstract}
RESUMO
A interrupção do processo de resfriamento do leite em pequenas propriedades representa uma constante preocupação para os produtores rurais, visto que coloca em risco a integridade do produto a ser comercializado. Essa realidade é o que motivou a realização deste trabalho, cujo objetivo consistiu em desenvolver e apresentar o conceito de um sistema que pudesse auxiliar os pequenos produtores a diminuírem as perdas ocasionadas pela falta de energia elétrica no processo de resfriamento do leite. $\mathrm{O}$ modelo proposto utiliza a plataforma de prototipagem Arduino em conjunto com outros componentes eletrônicos para realizar o monitoramento da rede de alimentação do resfriador e, sob a condição de falta, alertar os produtores por meio de indicação sonora e do envio de mensagens SMS, a fim de que os mesmos possam tomar ações necessárias o mais rápido possível. O módulo SIM800L foi utilizado para a comunicação via dados GSM, permitindo assim o acesso do sistema à rede de telefonia celular e o contato com os usuários, independentemente de onde estiverem. Para prover a alimentação do protótipo durante a interrupção de energia foi utilizada uma bateria de chumbo-ácido do tipo estacionária com tensão nominal de $12 \mathrm{~V}$.Os testes realizados mostraram que a bateria garante a autonomia necessária para que o sistema envie as mensagens de aviso e realize o acionamento do alarme no momento da falta.
\end{abstract}

Palavras-chave: Arduino. GSM. Resfriamento do leite.

\section{INTRODUÇÃO}

Nos últimos anos, a pecuária leiteira nacional vem lidando com novos desafios em sua cadeia produtiva sendo que, além do histórico aumento dos custos de produção, cita-se também aspectos como a crescente percepção dos consumidores quanto à segurança alimentar, o bem-estar animal e os impactos ambientais vinculados à agropecuária. Neste

\footnotetext{
${ }^{1}$ Como citar este artigo: TEIXEIRA, Gabriel Ramos; CAMPOS, Gustavo Lobato. Sistema automatizado para redução de perdas associadas ao processo de refrigeração do leite em pequenas propriedades. ForScience: revista científica do IFMG, Formiga, v. 7, n. 1, e00410, jan./jun. 2019. DOI: 10.29069/forscience.2019v7n1.e410
}

\footnotetext{
${ }^{2}$ Autor para correspondência: Gabriel Ramos Teixeira. E-mail: gabrielramos.tx@gmail.com.
} 
cenário de desafios e margens de lucro reduzidas, a busca pelo aumento da eficiência dos sistemas de produção de leite é o principal caminho a ser seguido (CAMPOS, 2013).

Neste contexto, o estudo proposto nesse artigo está relacionado ao processo de produção de leite, especificamente na parte associada ao resfriamento do leite durante seu armazenamento na propriedade rural.

O processo de resfriamento é uma forma de evitar que as propriedades nutritivas do leite sirvam de meio de cultura para micro-organismos que depreciam sua qualidade (RECHE, 2013), assim como aumentar o tempo de armazenamento do mesmo na fazenda, de modo a reduzir custos de transporte ao laticínio. Importante também citar que a partir da Instrução Normativa 51 (BRASIL, 2002), o Ministério da Agricultura, Pecuária e Abastecimento (MAPA), passou a exigir o resfriamento na propriedade leiteira (BARBOSA; JATOBÁ; BATISTA, 2008). Cita-se ainda que a norma para conservação da qualidade do leite, em quase todas as regiões de pecuária leiteira desenvolvida, exige que o mesmo seja resfriado a uma temperatura igual ou inferior a $10^{\circ} \mathrm{C}$ na primeira hora, caindo para $4^{\circ} \mathrm{C}$ nas duas horas após a ordenha, mantendo-se, assim, a qualidade desse leite (TORRES; OLIVEIRA; SOUZA, 2001).

Atualmente, o processo de armazenamento do leite se inicia após a coleta do produto in natura, seguindo para a sua estocagem e acondicionamento em tanques de resfriamento sob temperatura controlada, até que o mesmo seja recolhido por caminhões-tanques isotérmicos, o que ocorre, em geral, a cada dois dias.

Contudo, esse sistema não é "inteligente", e apesar de controlar a temperatura do leite, deixa de controlar um parâmetro de fundamental importância, o qual tem gerado perdas consideráveis ao produtor leiteiro. Não existe controle da alimentação do equipamento em questão, ou seja, se por alguma condição inesperada a energia acabar, ou temporariamente faltar, e nenhum funcionário da fazenda perceber, o leite deixará de ter sua temperatura controlada, e assim não será mais considerado próprio para venda ao laticínio, gerando grande perda monetária ao produtor. Desta forma, este artigo tem por ideia atuar justamente nesta lacuna do processo atualmente empregado.

Com essa finalidade, foi proposto um sistema automatizado capaz de alertar o produtor rural no instante em que o sistema de resfriamento do leite deixar de ser alimentado pela rede elétrica. Apesar do fato de essa proposta não resolver o problema da falta de energia por si só, acredita-se que ela possa diminuir o tempo decorrido entre o acontecimento da falha e a sua detecção pelos responsáveis, aumentando assim as chances de se reestabelecer o 
fornecimento de energia ou de se tomar outra decisão viável antes que toda a produção se perca.

Assim, nas seções seguintes apresenta-se o referencial de alguns conceitos pertinentes ao sistema proposto, bem com o seu desenvolvimento e os resultados obtidos.

\section{REFERENCIAL TEÓRICO}

\subsection{Sistemas embarcados}

Atualmente, presencia-se uma crescente utilização de sistemas embarcados em praticamente todos os equipamentos eletrônicos disponibilizados no mercado.

Segundo Pereira et al. (2015), a palavra embarcado pode ser relacionada ao fato de ser uma parte funcional de um sistema como um todo, ou seja, um software embarcado é responsável por uma determinada função em um sistema maior, de maneira contínua e, de preferência, sem travamentos ou panes.

Assim, para o indivíduo que programa e desenvolve um sistema embarcado ele pode ser representado como um conjunto de entradas, saídas, processadores e memórias, que se relacionam entre si e com o ambiente onde será utilizado, como pode ser visto na FIG. 1. Já o usuário final se preocupa apenas em como utilizar este sistema e o que ele agrega de valor a um produto, em termos de redução de custos, aumento de funcionalidade, aumento de desempenho, entre outros. (CUNHA, 2007).

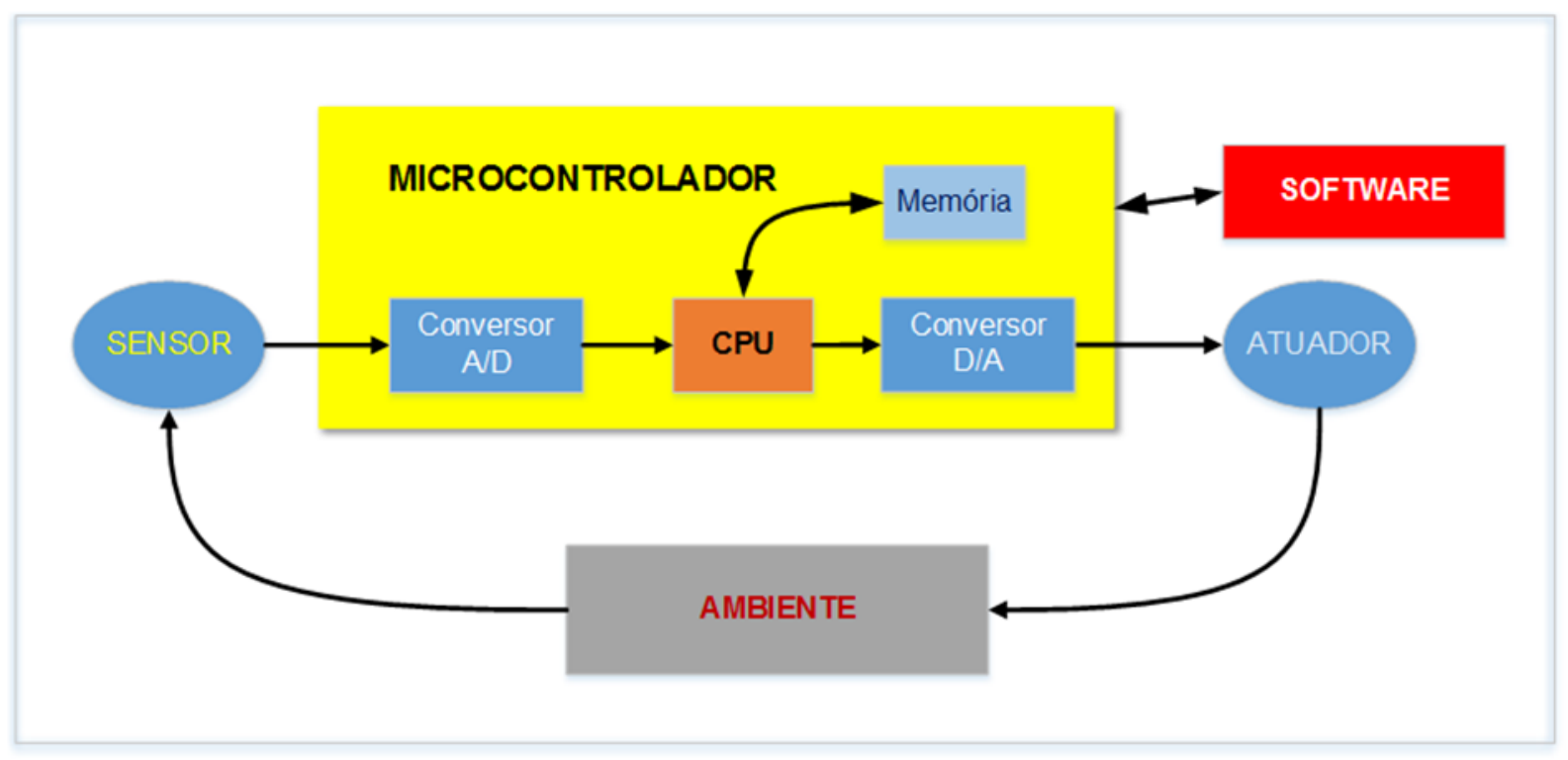

Figura 1 - Elementos básicos de um sistema embarcado Fonte: Adaptação de Cunha (2007). 
Conforme pode ser visto na FIG. 1, um sistema embarcado necessita de um componente de controle que gerencie todo o funcionamento do sistema. A opção ideal para isso é utilizar um microcontrolador, já que ele tem a capacidade de fazer a leitura dos sinais externos, executar programas com as tarefas definidas, processar os sinais e enviar para atuadores os resultados esperados (CUNHA, 2007).

Os microcontroladores surgiram no princípio dos anos 80, como uma evolução natural dos circuitos digitais que foram se tornando complexos e começaram a ser substituídos por unidades de processamento encapsuladas em um único chip, junto com memórias, clock e periféricos mais limitados que um computador (PENIDO; TRINDADE, 2013).

De maneira geral, um microcontrolador é composto por um circuito integrado programável que contém toda a estrutura (arquitetura) de um microcomputador, isto é, em sua estrutura interna podemos encontrar uma CPU (unidade central de processamento), memória RAM, memória EEPROM (memória de leitura e escrita não volátil) e portas de entrada/saída (pinos de E/S) (OKI; MANTOVANI, 2013).

Para facilitar ainda mais o desenvolvimento de sistemas utilizando microcontroladores é possível acoplá-los a estruturas auxiliares, conhecidas como plataformas de prototipagem. A próxima seção trata de uma dessas plataformas, a Arduino, muito utilizada atualmente em aplicações didáticas e projetos eletrônicos.

\subsection{Plataforma Arduino}

Arduino é uma plataforma open source de prototipagem eletrônica, baseada em hardware e software flexíveis e de fácil implementação. Ela é capaz de "interagir" com o ambiente, por meio de sinais de entrada provenientes de uma variedade de sensores, e modificá-lo através de sinais de saídas para atuadores, motores, luzes, etc. (PEIXOTO et al., 2012).

Existe no mercado uma série de versões da placa Arduino, todas baseadas em um microprocessador de 8 bits da família Atmel AVR, que pode ser programado usando a linguagem de programação padrão do Arduino, que é essencialmente $\mathrm{C} / \mathrm{C}++$, e um ambiente de desenvolvimento, baseado no ambiente Processing (EVANS; NOBLE; HOCHENBAUM, 2013).

O hardware das placas Arduino, em geral, é composto por um microprocessador Atmel AVR, um cristal ou oscilador para gerar os pulsos da frequência de operação e um regulador linear de 5V. Dependendo do modelo, elas podem possuir uma saída USB, que 
permite conectá-las a um computador para upload ou recuperação dos dados. A placa apresenta ainda pinos de entrada e saída do microcontrolador, possibilitando a conexão com outros circuitos ou sensores (MCROBERTS, 2011).

O Arduino possui portas analógicas e digitais. Enquanto a comunicação digital só pode assumir dois estados bem definidos, HIGH (5V) ou LOW (0V), as portas analógicas conseguem registrar qualquer valor de tensão entre 0 e 5V. Porém, mesmo registrando valores analógicos, o seu microcontrolador trabalha internamente com dados digitais. Por este motivo ele possui um conversor analógico/digital interno com 10 bits de resolução (ARDUINO, 2016).

Não bastasse a gama de funcionalidades disponíveis nas placas Arduino, elas podem ainda ser estendidas utilizando os shields, que são placas de circuito contendo outros dispositivos (por exemplo, receptores GPS, displays de LCD, módulos de Ethernet etc.), que podem ser simplesmente conectadas ao Arduino para obter funcionalidades adicionais (MCROBERTS, 2011).

Neste sentido, é destacada a seguir uma funcionalidade utilizada em conjunto com a plataforma Arduino.

\subsection{SMS (Short Message Service)}

O Serviço de Mensagens Curtas (SMS), surgiu em 1991 na Europa, incluído no padrão de segunda geração digital GSM. O SMS ponto a ponto provê um mecanismo para transmissão de e para terminais móveis sem fio. Uma característica importante deste serviço é que ele permite a um terminal móvel receber ou enviar a qualquer momento, independentemente de chamada de voz ou dados em andamento. Além disso, a entrega das mensagens é garantida pela rede. Falhas temporárias são identificadas e a mensagem curta é armazenada na rede até que o destino esteja novamente disponível (DIAS; SADOK, 2001).

O texto das mensagens SMS possui um tamanho máximo de 160 caracteres (letras, números ou símbolos no alfabeto latino) (ERICKSON, 2012). Em 2010, o SMS foi o sistema de envio de dados mais utilizado, adotado por $80 \%$ dos usuários de telefonia móvel. Embora o seu uso tenha diminuído consideravelmente nos últimos anos devido a popularização dos smartphones e dos serviços de mensagens via internet, o serviço SMS ainda é a maneira mais eficaz de alcançar os usuários, principalmente em áreas remotas ou mais isoladas. Isso acontece porque ele não exige a conexão com a internet, tornando acessível a comunicação com qualquer um com acesso a rede de telefonia (TOLENTINO, 2015). 


\subsection{Baterias}

As baterias podem ser definidas como associações em série ou paralelo de células unitárias, o que permite uma grande diversidade de valores de tensões ou correntes elétricas para diferentes tipos de aplicação. Cada uma dessas células possui a capacidade de acumular energia, conservá-la e restituí-la em momentos oportunos, constituindo assim uma fonte autônoma de energia (CHAGAS, 2007; BECKER, 2017).

Conforme Chagas (2007) afirma, as baterias são divididas em duas principais categorias, sendo classificadas como primárias (não recarregáveis) ou secundárias (recarregáveis). Nesse segundo grupo estão incluídas as baterias do tipo chumbo-ácido, que podem ser utilizadas nas mais diversas aplicações, como na partida de automóveis, em sistemas nobreaks, iluminações de emergência, alarmes, centrais telefônicas, etc.

Devido à variedade de aplicações, cada tipo de bateria é desenvolvido de forma a atender com eficiência a funcionalidade para a qual foi desenvolvida. Assim, cada modelo possui características e valores nominais que os diferenciam das demais (CARNEIRO et al., 2017). A seguir são elencados alguns parâmetros que definem uma bateria do tipo chumboácido.

\subsubsection{Capacidade nominal}

A capacidade nominal $\left(C_{n}\right)$, expressa em Ampère-hora $(A h)$, é a unidade que mensura o armazenamento energético de uma bateria, também conhecido como autonomia. Indica a quantidade de energia que ela possui ao ser fabricada e estar plenamente carregada, ou seja, o quanto de corrente, em Ampère (A), que a bateria é capaz de fornecer em um determinado período de horas (h) sob certas condições específicas (OLIVEIRA, 2016).

A definição de $\mathrm{C}_{\mathrm{n}}$ é extremamente dependente do tempo de descarga. Por esse motivo, ela deve ser realizada com base em um regime de análise padrão de 10 ou 20 horas, dependendo de cada fabricante. Assim, a capacidade nominal pode ser calculada pela Eq. (1) (SEGUEL, 2009).

$$
C_{\mathrm{n}}=I x t
$$

Onde: 
$\mathrm{C}_{\mathrm{n}}=$ Capacidade nominal da bateria $(\mathrm{Ah})$

$\mathrm{I}=$ Corrente de descarga usada nos testes (A)

$\mathrm{t}=$ Tempo da descarga $(\mathrm{h})$.

As baterias apresentam um comportamento não linear, isto é, quanto maior a corrente de descarga, menor será a autonomia e a capacidade. Por isso, não é correto falar em uma bateria de 100Ah. Deve-se falar, por exemplo, em uma bateria de 100Ah, com padrão de descarga 20 horas, o que significa que esta bateria permitirá descarga de $100 / 20=5 \mathrm{~A}$, durante 20 horas (UNICOBA, [2016]).

\subsubsection{Valores de tensão}

Em geral, as baterias são internamente compostas por um arranjo em série de alguns elementos unitários, ou células, de aproximadamente $2 \mathrm{~V}$. O valor da tensão nominal que define um dispositivo depende do número de células que o compõe. Desta forma, uma bateria composta por seis dessas unidades possui uma tensão nominal de 12V (CHAGAS, 2007).

Apesar de possuir esse valor nominal de tensão, as baterias costumam perder naturalmente a sua carga armazenada, mesmo que não estejam sendo utilizadas. Esse fenômeno, conhecido como autodescarga, pode fazer com que a tensão nos terminais do elemento diminua a uma taxa de 2 a $5 \%$ ao mês, prejudicando assim a sua capacidade de fornecimento de energia (CARNEIRO et al., 2017).

Para se evitar as perdas por autodescarga, é recomendado a aplicação de uma tensão de manutenção na bateria, chamada de tensão de flutuação. Quando submetidas a uma tensão de flutuação correta, as baterias são mantidas carregadas e prontas para fornecerem sua capacidade nominal, uma vez que o fluxo de corrente de flutuação compensa as perdas. A tensão de flutuação depende da temperatura e do tipo de bateria, mas a maioria das baterias de chumbo- ácido possui uma tensão de flutuação da ordem de 2,20 a 2,30V por elemento, a uma temperatura ambiente de $25^{\circ} \mathrm{C}$ (CHAGAS, 2007).

Outro valor de tensão que merece atenção é o limiar de descarga da bateria, isto é, o menor valor de tensão que é permitido a um elemento de bateria chumbo-ácido atingir durante uma descarga. Normalmente, o valor da tensão final de descarga ou tensão de corte é estipulado em $1,75 \mathrm{~V}$ por elemento. Valores de tensão inferiores a estes podem danificar o elemento irreversivelmente devido à sulfatação das placas ou a inversão de polaridade das mesmas, podendo até inutilizar a bateria (CHAGAS, 2007). 
Desta forma, com base nas informações contidas neste referencial, o próximo tópico apresenta as metodologias empregadas no desenvolvimento do modelo proposto, assim como as partes que o compõe.

\section{MATERIAIS E MÉTODOS}

A FIG. 2, a seguir, mostra a representação esquemática do modelo proposto para auxiliar os produtores na diminuição das perdas provocadas pela interrupção do processo de resfriamento do leite. Nela é possível identificar os módulos que constituem o sistema de indicação de falta de energia, os quais são descritos em seguida.

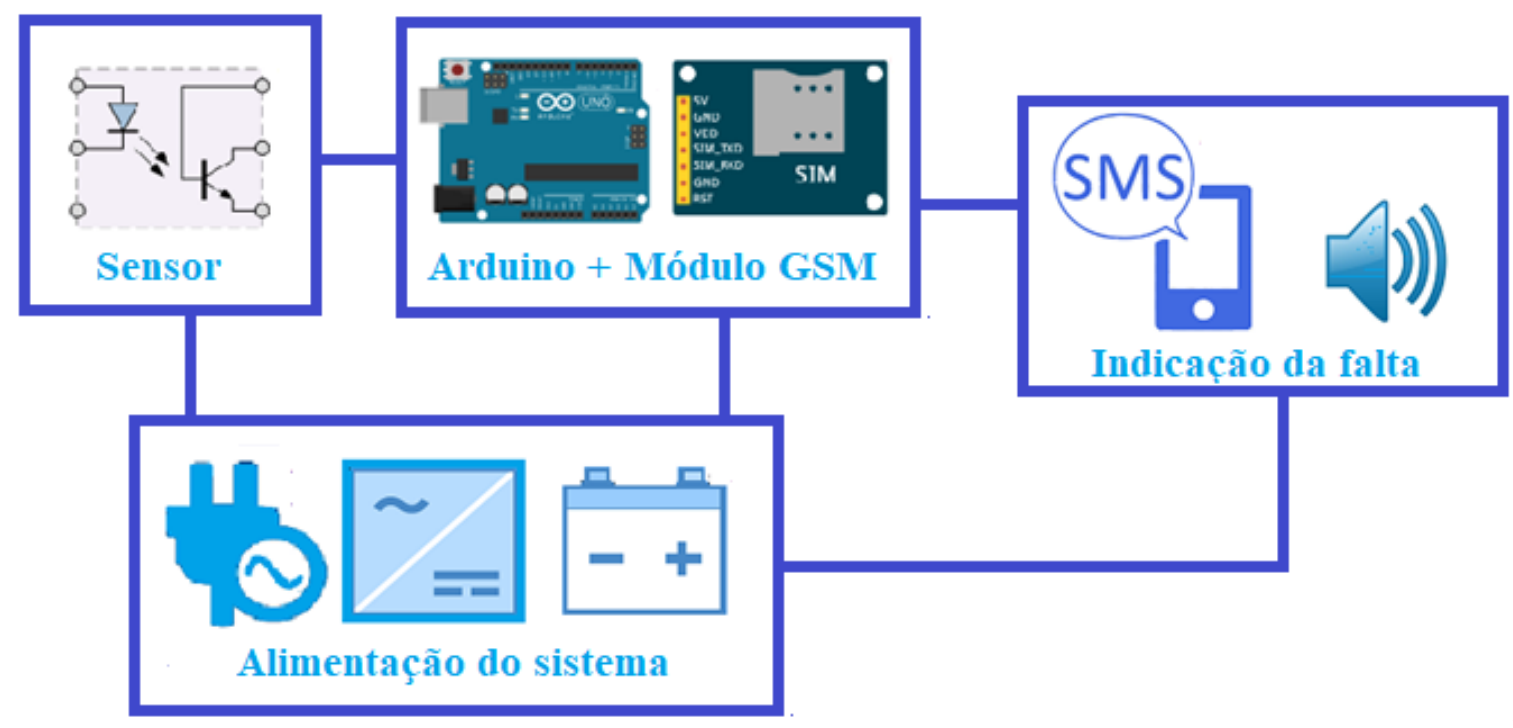

Figura 2 - Representação do sistema proposto Fonte: Do autor (2019).

\subsection{Alimentação do sistema}

O sistema proposto deve ser conectado à mesma rede que alimenta o dispositivo de resfriamento do leite a ser monitorado. Como a grande maioria dos resfriadores funciona em $220 \mathrm{~V}$, este nível de tensão também foi considerado no desenvolvimento do protótipo de forma que ele possa operar nele. É interessante que se diga que quanto menor for a distância de conexão entre o sistema e o dispositivo a ser monitorado, maiores são as chances de se detectar outras possíveis causas de desligamento local, como rompimento de cabos na rede interna, que poderiam passar despercebidas.

Como a alimentação do resfriador é feita em corrente alternada, faz-se necessário o uso de um conversor AC/DC para adequar os níveis de tensão entre a rede e o sistema. Além 
disso, a bateria usada como fonte alternativa durante a condição de falta precisa de um circuito de carga adequado para armazenar energia. Desta forma, para atender essas necessidades foram utilizados o conversor AC/DC e o circuito de carga da bateria propostos por Teixeira e Campos (2017).

\subsection{Sensor}

Como o objetivo principal da proposta consiste na leitura da rede de energia elétrica, faz-se necessário um elemento sensor que realize essa função. Tal elemento deve ser capaz de transmitir à central de controle o estado em que se encontra o fornecimento de energia, ou seja, se existe ou não tensão no ponto observado. É importante ressaltar que para isso necessita-se de um componente que consiga reproduzir em sua saída um sinal apropriado à análise do microcontrolador ( 0 a 5 volts), sendo que em sua entrada é aplicada uma tensão alternada com nível relativamente alto.

Assim, para satisfazer essas necessidades, viu-se como uma boa alternativa o emprego de um optoacoplador devido a sua capacidade de funcionar como um interruptor ativado opticamente e também por permitir o isolamento elétrico entre as partes envolvidas. $\mathrm{O}$ esquema de ligação do optoacoplador para esta aplicação é apresentado na FIG. 3.

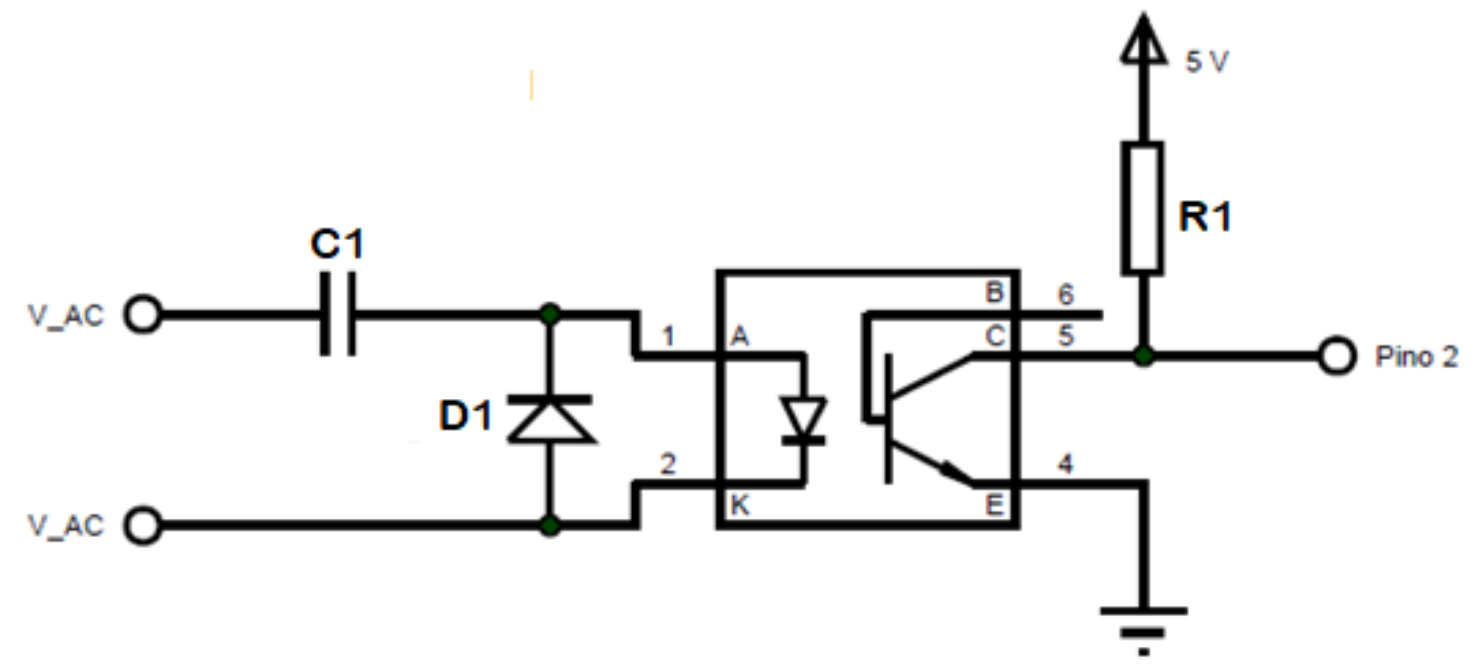

Figura 3 - Circuito detector de tensão

Fonte: Do autor (2018).

Como indicado na FIG. 3, a entrada do optoacoplador é conectada à rede de alimentação do resfriador. Desta forma, quando houver tensão na rede, a saída do sensor, conectada ao pino 2 do Arduino apresenta um nível lógico baixo (0V). Já o contrário ocorre quando a entrada não é alimentada e o sensor detecta a situação de falta enviando um sinal 
com nível lógico alto (5V), que é interpretado pelo microcontrolador como condição para acionar as rotinas de alarme.

\subsection{Arduino + Módulo GSM}

Para realizar as funções de controle do protótipo escolheu-se a placa Arduino UNO R3 que conta com uma versão atualizada da plataforma Arduino. O seu uso se justifica pelo fato de apresentar grande robustez e praticidade, além de ser ideal para projetos como o que aqui se apresenta por causa do número reduzido de entradas e saídas a serem controladas. A FIG. 4 apresenta o hardware que constitui a placa Arduino Uno e a disposição dos seus principais elementos.

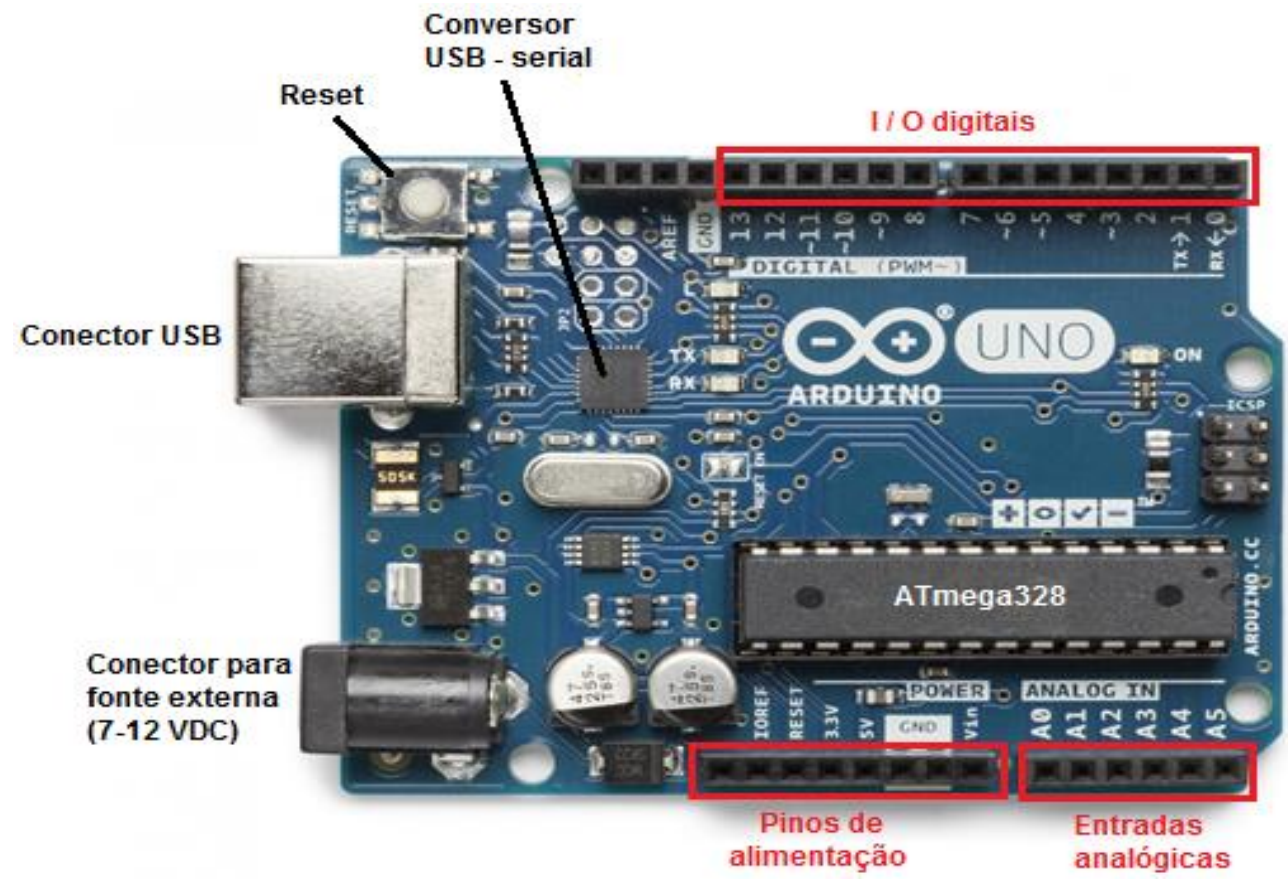

Figura 4 - Arduino UNO

Fonte: Adaptada de ArduinoCC (2018).

Como se vê na FIG. 4, o Arduino Uno conta com uma entrada USB para comunicação com dispositivos como notebooks e computadores, por onde são transferidos os códigos programados na IDE. Seu microcontrolador é um ATMEL ATMEGA328 de 8 bits, com 32 KB de memória flash, o que permite o processamento de pequenas quantidades de dados. Ele possui um total de 28 pinos, sendo que 14 pinos são reservados para entrada ou saída digitais 
e mais 6 para entradas analógicas. Os 8 pinos restantes são para alimentação de circuitos externos.

Para que se possa alertar remotamente o usuário da falta, é utilizado um módulo GSM/GPRS em conjunto com a placa Arduino. Esse módulo consiste no chip SIM800L Quad-band da SIMCom (SIMCOM, 2005), arranjado numa pequena estrutura que permite o acesso aos seus pinos de controle e de alimentação e possibilita a comunicação com o microcontrolador. Além disso, possui um slot para acoplamento de um cartão SIM de identificação, permitindo a utilização de qualquer uma das operadoras disponíveis para fornecer os serviços de telefonia. Na Figura 5 apresenta-se o módulo GSM SIM800L, assim como a identificação de seus pinos e disposição de alguns componentes.
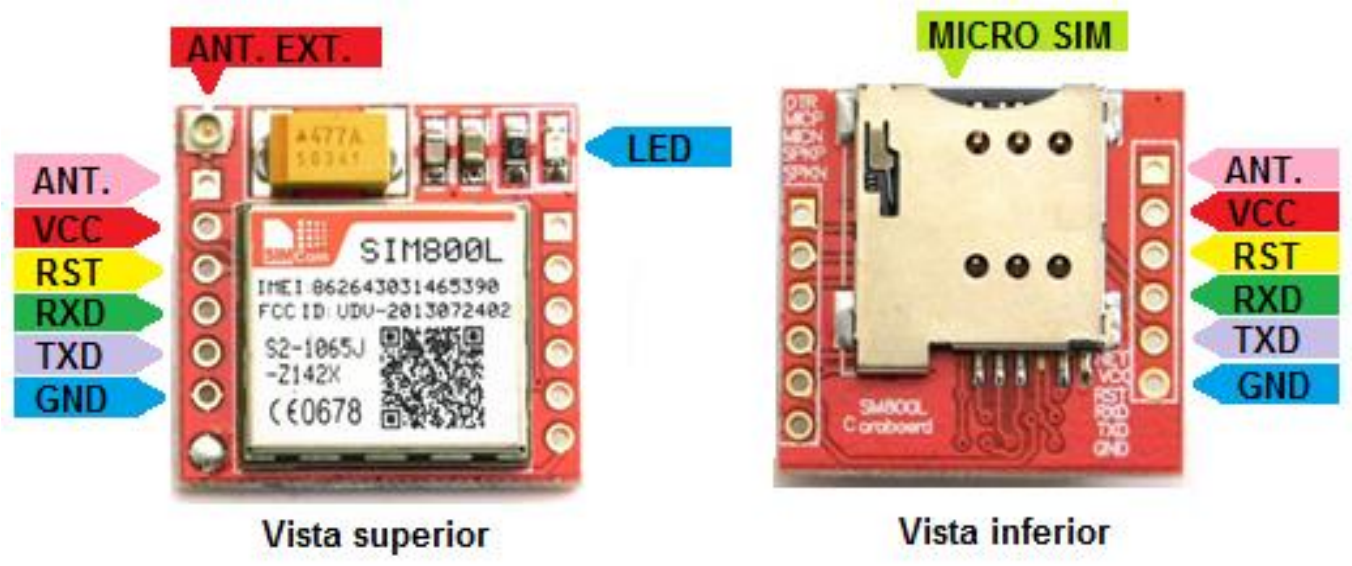

Figura 5 - Módulo GSM SIM800L

Fonte: Adaptada de Nettigo (2018).

A alimentação do módulo GSM deve ser feita num nível de tensão entre 3,6V e 4,4V, segundo dados do fabricante (SIMCOM, 2005). Assim, para adequar a tensão disponível no sistema à esta faixa de valores, é empregado um conversor DC/DC.

A comunicação entre o módulo GSM e o Arduino é realizada via interface serial à dois fios. Como o Arduino já possui uma porta serial destinada especificamente para a comunicação via USB, é necessário definir por software uma nova porta serial para receber e transmitir as informações. A biblioteca SoftwareSerial, presente na IDE do Arduino, permite destinar qualquer uma das portas do microcontrolador para realizar essa comunicação (EVANS; NOBLE; HOCHENBAUM, 2013).

Para facilitar ainda mais a utilização do módulo GSM, utiliza-se a biblioteca Sim800L, criada por Cristian Steib (STEIB, 2018). Ela pode ser instalada junto com o acervo de bibliotecas da IDE do Arduino e usada para enviar e receber os comandos de forma simples e 
organizada. Importante dizer que essa biblioteca destina automaticamente os pinos 10 e 11 do Arduino para a comunicação serial, condição que deve ser respeitada para o bom funcionamento do sistema. A TAB. 1 apresenta as principais funções da biblioteca Sim8001, bem como uma breve descrição de cada uma delas.

Tabela 1 - Principais funções da biblioteca Sim800L

\begin{tabular}{cl}
\hline Função & \multicolumn{1}{c}{ Descrição } \\
\hline Begin & Inicializa a biblioteca Sim8001 \\
Envia a mensagem SMS definida pelo parâmetro text para o \\
destinatário number, que deve ser um número válido de celular. \\
readSms (index) & Lê a mensagem SMS armazenada na posição index da memória. \\
getNumberSms (index) & $\begin{array}{l}\text { Identifica o número do remetente da mensagem SMS armazenada } \\
\text { na posição index da memória }\end{array}$ \\
delAllSms & Apaga todas as mensagens armazenadas na memória \\
\hline
\end{tabular}

Fonte: Adaptada de Steib (2018).

\subsection{Indicação de falta}

O alerta enviado por meio de mensagem SMS representa uma estratégia eficiente para o produtor, pois concede a ele a chance de ter conhecimento da falta, mesmo não estando presente na propriedade. Entretanto, para que isso ocorra, o usuário deve cadastrar o número do telefone no qual deseja receber o aviso. Isso deve ser realizado ao se enviar uma mensagem para o número do cartão SIM presente no módulo GSM, contendo um código predefinido e o número do celular do usuário. O número será armazenado pelo microcontrolador e utilizado no envio das mensagens de alerta.

Para que a falha também seja identificada pelas pessoas presentes no local, utiliza-se uma sirene, que soará no momento da ocorrência. Como o funcionamento desse dispositivo de indicação deve ser controlado pelo Arduino, necessita-se de um componente que realize o acionamento por meio do sinal presente em uma das portas digitais do microcontrolador. Essa função é bem executada por um módulo relé, que é próprio para ser utilizado em conjunto com o Arduino na atuação de cargas diversas. Ao ser acionado, o módulo relé alimenta a sirene com a tensão presente nos terminais da bateria, o que indicará a falta de energia. A FIG. 6 ilustra a conexão entre o módulo relé e a sirene utilizada no sistema. 


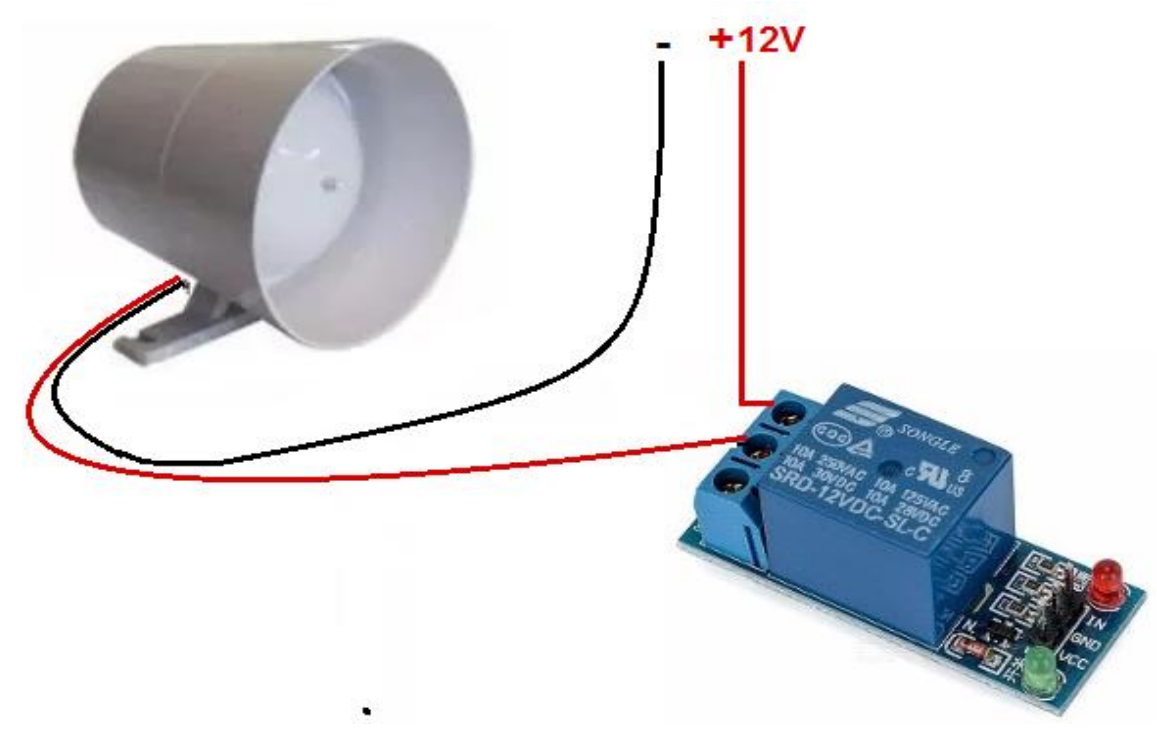

Figura 6 - Conexão entre módulo relé e sirene Fonte: Do autor (2018).

\section{RESULTADOS E DISCUSSÕES}

A fim de se verificar o funcionamento do modelo proposto, realizou-se uma série de testes, avaliando primeiramente o comportamento individual de algumas partes e, em seguida, do sistema como um todo.

\subsection{Resposta do detector de tensão da rede}

A análise do detector de tensão é feita por meio do sinal obtido na saída do sensor. Com o auxílio de um osciloscópio, observou-se a forma de onda que define essa resposta, conforme apresenta a FIG. 7, sendo que nela é possível ver o comportamento do sensor nas duas condições que interessam para o controle do sistema.

$\mathrm{Na}$ primeira parte do sinal da FIG. 7, identificada pela ocorrência de pulsos em pequenos intervalos de tempo, tem-se a resposta do sensor para condição de fornecimento de energia. Dado o comportamento senoidal da tensão de entrada, para cada semiciclo positivo obtêm-se um pulso em nível lógico baixo na saída e outro pulso em nível lógico alto para os semiciclos negativos, formando assim uma forma de onda pulsante. Já para a ocorrência da falta de energia, como evidencia o restante do sinal, a resposta permanece constante em nível lógico alto. 


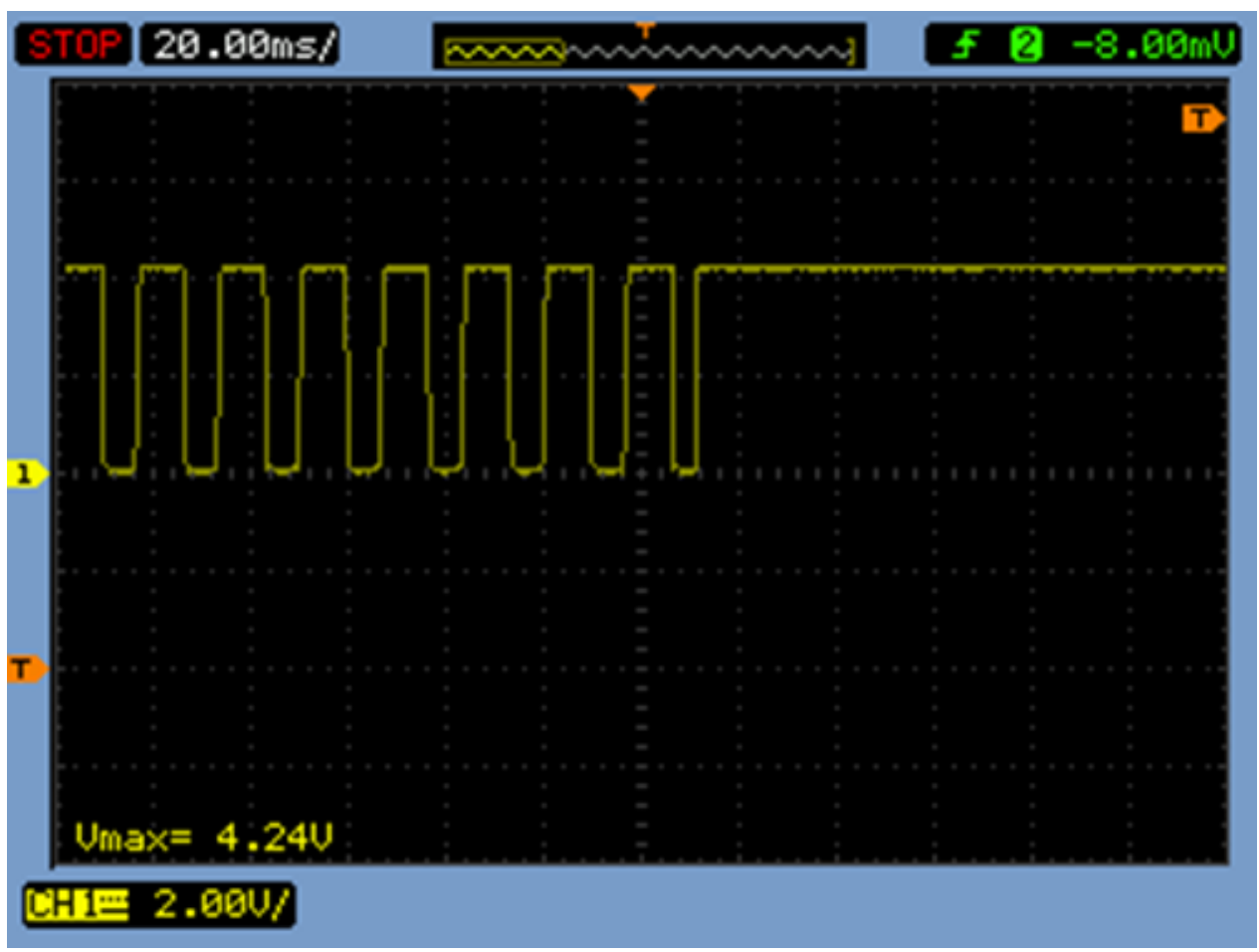

Figura 7 - Sinal obtido na saída do detector de tensão Fonte: Do autor (2018).

Assim, cabe ao microcontrolador analisar o sinal na saída do detector e identificar o tempo transcorrido entre dois pulsos em nível alto. Caso esse tempo seja maior do que o intervalo natural de comutação da rede, a condição de anormalidade deve ser detectada e as devidas ações de alerta executadas.

\subsection{Descarga da bateria}

Durante o período de ocorrência da falta de energia elétrica, o sistema é unicamente alimentado pela bateria. Sob essa condição, a tensão nos terminais desse elemento foi monitorada para verificar a sua autonomia. Foram coletados dados para a construção da curva aproximada da descarga da bateria, que pode ser visualizada na FIG. 8. Nela, observa-se que o decaimento da carga se dá num intervalo de 8 horas, período em que o sistema executa as devidas ações de alerta e consome uma corrente média de 400mA. 


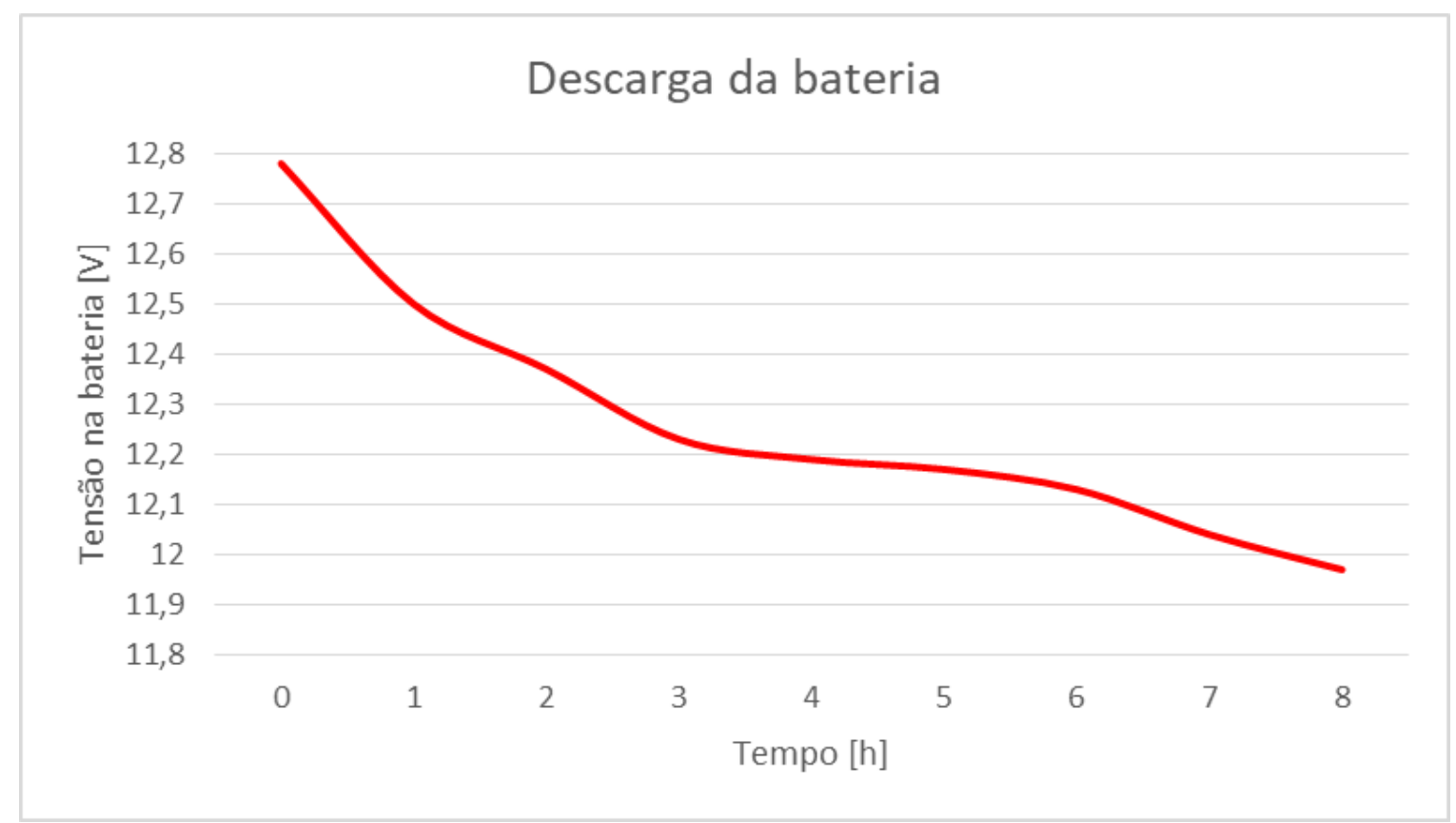

Figura 8 - Curva de descarga da bateria Fonte: Do autor (2018).

Apesar do teste não ter sido realizado até o ponto de tensão de corte da bateria, avaliase que o período analisado é suficiente para comprovar a autonomia do sistema, além de evidenciar uma profundidade de descarga consideravelmente baixa. Uma vez que se espera que dentro deste prazo a alimentação da rede seja reestabelecida, é possível assumir a garantia de funcionamento do alarme.

\subsection{Carga da bateria}

Em sequência, o processo de carga também foi registrado. Considerando a condição inicial após o retorno do fornecimento de energia, novas leituras são feitas nos terminais da bateria, tanto para obter a tensão como feito anteriormente quanto para mensurar a corrente de carga, utilizando um amperímetro. O comportamento destas grandezas é apresentado na FIG. 9, onde se observa o aumento da tensão ao longo do período de carga, ao mesmo tempo que a corrente diminui. Ao fim do processo, a bateria permanece em flutuação, requisitando apenas um pequeno valor de corrente para a manutenção de sua carga. 


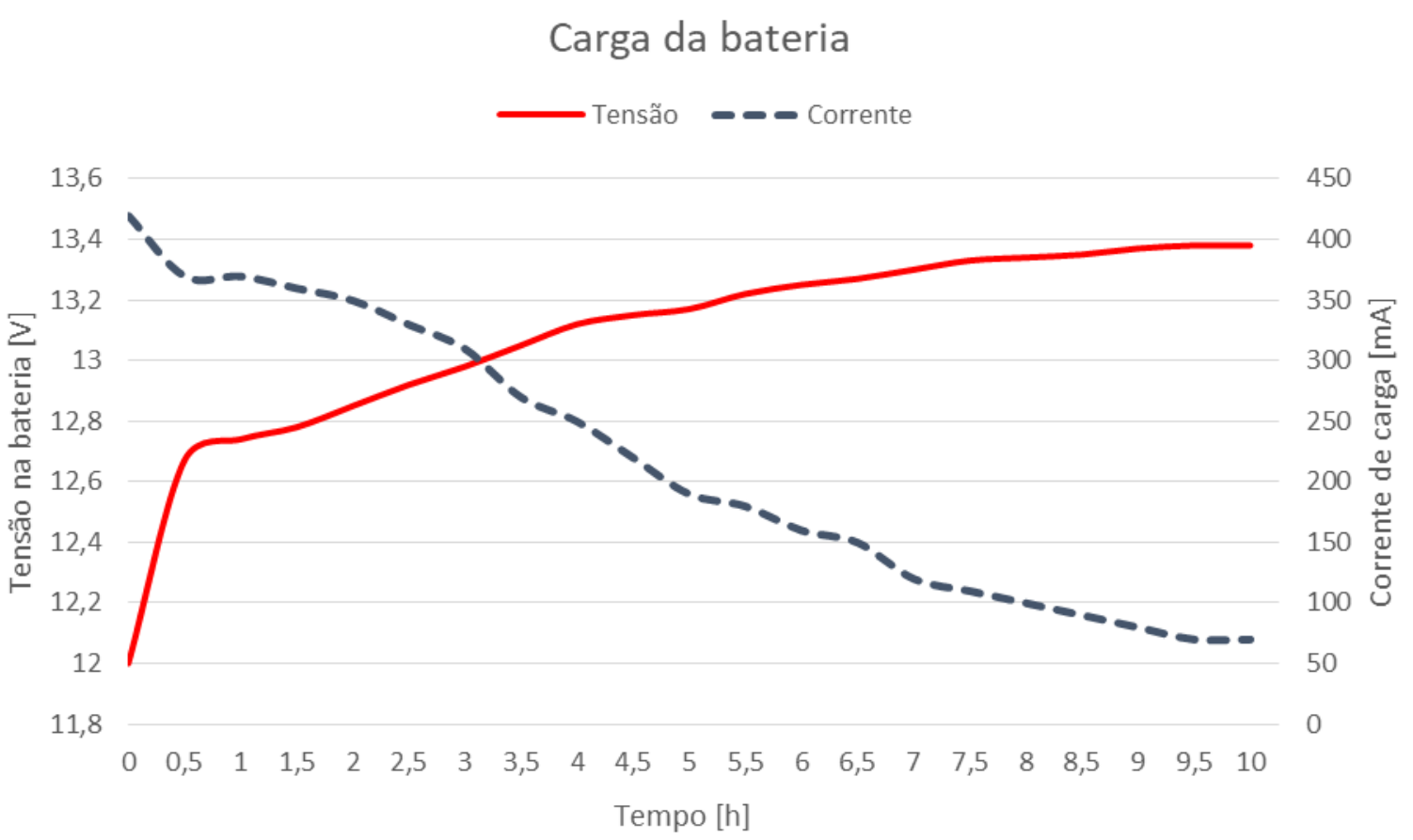

Figura 9 - Processo de carga da bateria Fonte: Do autor (2018).

\subsection{Envio das mensagens SMS}

Por fim o funcionamento do sistema foi atestado por meio das mensagens SMS recebidas e enviadas durante a execução das tarefas de monitoramento e alerta. A primeira troca de mensagens é feita com o intuito de cadastrar o usuário para o envio das futuras mensagens, conforme ilustra a FIG. 10. A mensagem de cadastro possui um código predefinido para evitar que outros números sejam armazenados como destinatários no sistema de controle. 


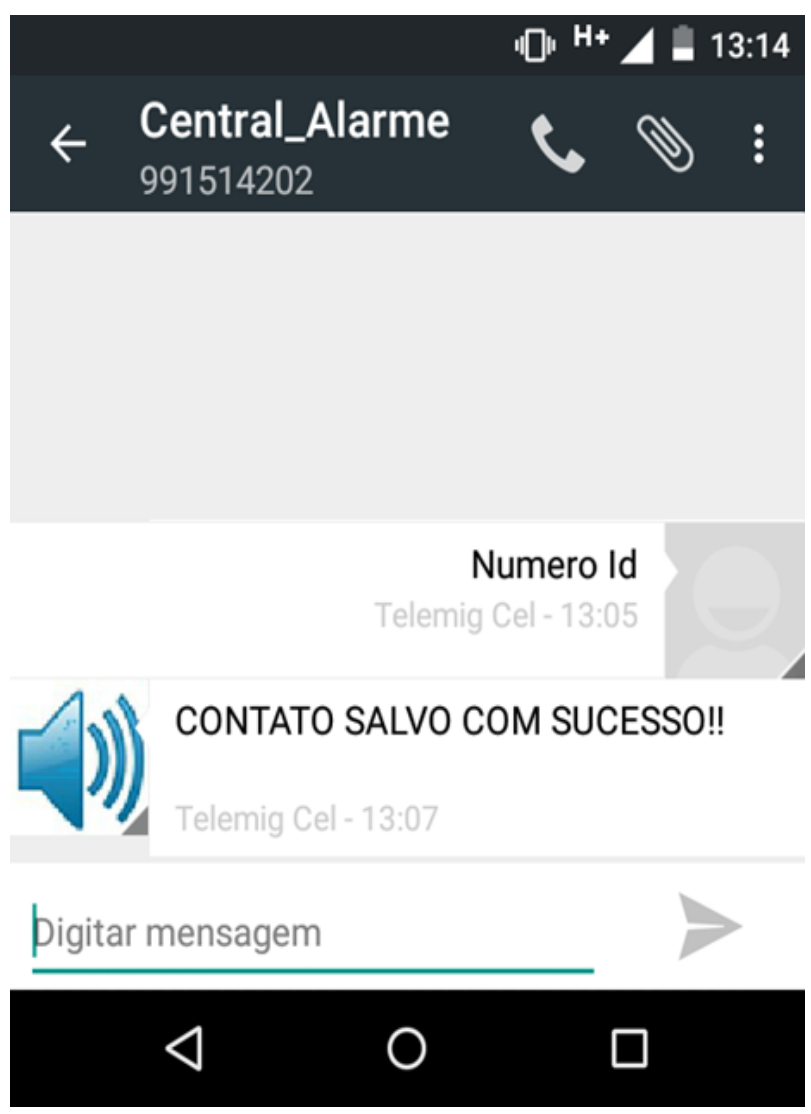

Figura 10 - Mensagem inicial de cadastro do usuário Fonte: Do autor (2018).

Realizado o cadastramento, o sistema é submetido a uma condição de falta. Ao receber a mensagem de alerta o usuário pode optar por desligar remotamente o alarme sonoro enviando um comando específico. O comando recebido é executado e confirmado pela central, que continua monitorando o estado da rede. Quando as devidas ações são efetuadas e a falta é solucionada, uma última mensagem é enviada para informar o usuário. Essa troca de mensagens é identificada na FIG. 11 a). Outra possibilidade existente é a de que o alarme seja percebido e desligado localmente por alguma pessoa presente na propriedade. Caso isso ocorra o proprietário também é informado por meio de uma mensagem e pode aguardar apenas a confirmação do retorno à normalidade do sistema, conforme a FIG. 11 b). 


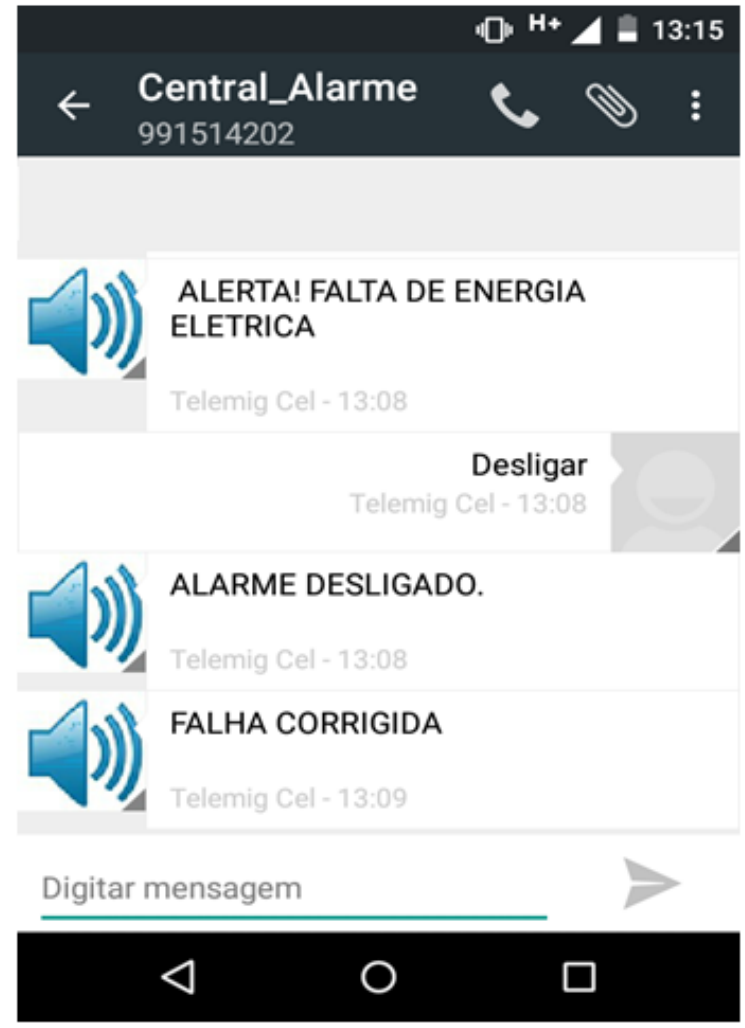

a) Alarme desligado remotamente

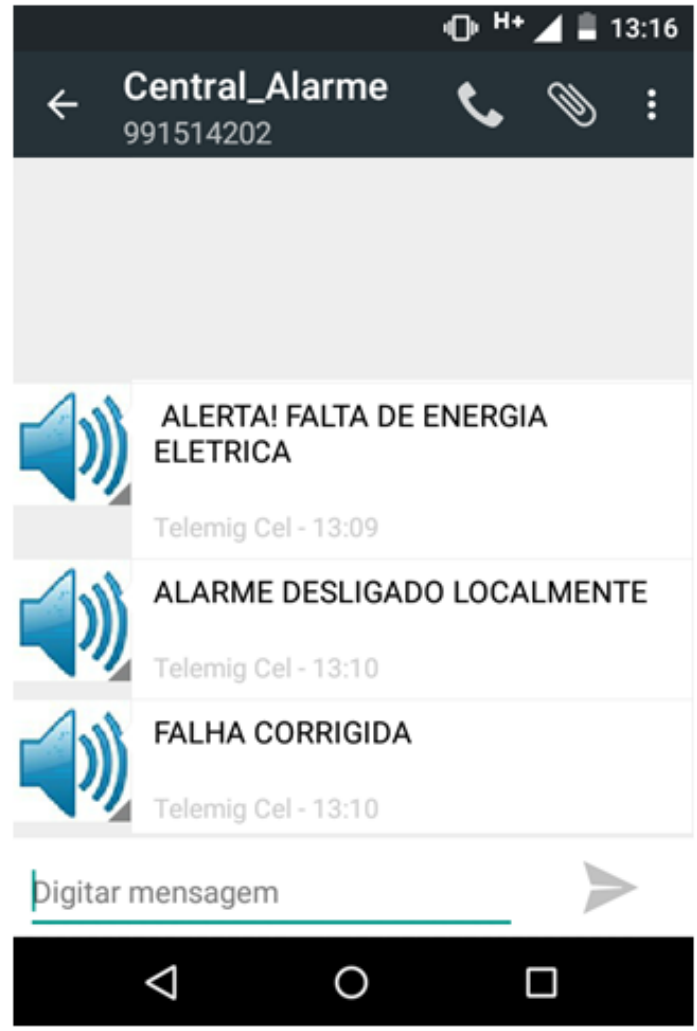

b) Alarme desligado localmente

Figura 11 - Troca de mensagens na condição de falta Fonte: Do autor (2018).

\section{CONCLUSÃO}

O modelo de sistema microcontrolado descrito nesse trabalho representa uma possível solução para a diminuição das perdas ocasionadas pela falta de energia elétrica durante o processo de resfriamento do leite em pequenas propriedades, visto que garante ao produtor a percepção da falta no instante em que esta ocorra, e assim, possibilita que o fornecimento de energia seja reestabelecido em um menor espaço de tempo. A capacidade do sistema de alertar o produtor tanto local quanto remotamente, via mensagens SMS, proporciona ao usuário uma maior liberdade para desenvolver suas demais atividades diárias sem se preocupar com o processo de resfriamento do leite.

Ao contrário das áreas urbanas onde a facilidade de acesso à internet possibilita um número maior de alternativas e funcionalidades para sistemas de automação e de comunicação remota, algumas áreas do meio rural ainda enfrentam certas dificuldades para conseguir inserir novas tecnologias em suas atividades. Conforme mostrado nesse trabalho, a utilização da rede GSM representa uma alternativa satisfatória para suprir a falta de acesso à internet 
encontrada em algumas localidades, permitindo a comunicação e o controle de sistemas como o que foi proposto.

Assim, o sistema apresentado atende aos objetivos propostos e pode ser aplicado para facilitar o processo de produção de leite em pequenas propriedades ou em qual outro seguimento onde as suas funcionalidades possam se tornar uteis.

\title{
AUTOMATED SYSTEM FOR REDUCING LOSSES ASSOCIATED WITH THE MILK COOLING PROCESS IN SMALL PROPERTIES
}

\begin{abstract}
The interruption of the milk cooling process on small farms is a constant concern for farmers, as it endangers the integrity of the product to be marketed. This reality is what motivated the accomplishment of this work, whose objective was to develop and present the concept of a system that could help the small producers to reduce the losses caused by the lack of electric energy in the process of cooling the milk. The proposed model uses the Arduino prototyping platform in conjunction with other electronic components to monitor the cooler supply network and, in case of failure, to alert producers by means of a sound indication and the sending of SMS messages in order to that they can take necessary actions as soon as possible. The SIM800L module was used for communication via GSM data, thus allowing the system access to the cellular telephone network and the contact with the users, no matter where they are. In order to provide power to the prototype during the power interruption, a lead-acid battery of the stationary type with nominal voltage of $12 \mathrm{~V}$ was used. The tests carried out showed that the battery guarantees the autonomy necessary for the system to send the warning messages and to carry out alarm at the time of the fault.
\end{abstract}

Keywords: Arduino. GSM. Cooling of milk.

\section{REFERÊNCIAS}

ARDUINO.CC. Arduino Uno Rev3. 2018. Disponível em:

https://store.arduino.cc/usa/arduino-uno-rev3. Acesso em: 18 abr. 2018.

BARBOSA, Severino Benone Paes; JATOBÁ, Raquel Bezerra; BATISTA, Ângela Maria Vieira. A Instrução Normativa 51 e a qualidade do leite na região nordeste e nos Estados do Pará e Tocantins. In: CONGRESSO BRASILEIRO DE QUALIDADE DO LEITE (CBQL), 3., 2008, Recife. Anais... Recife: CCS Gráfica e Editora, 2008, v. 1, p. 25-33.

BECKER, Luís Rodrigo. Análise experimental da qualidade da energia de uma microrrede fotovoltaica com back-up. 2017. 137 f. Dissertação (Mestrado em Engenharia Mecânica) - Programa de Pós-graduação em Engenharia Mecânica, Universidade do Vale do Rio dos Sinos, São Leopoldo, 2017. Disponível em: http://www.repositorio.jesuita.org.br/handle/UNISINOS/6430. Acesso em: 17 abr. 2018.

BRASIL. Ministério da Agricultura, Pecuária e Abastecimento. Instrução Normativa $\mathrm{N}^{\circ} 51$ de 18 de setembro de 2002. Regulamento Técnico de Produção, Identidade e Qualidade do Leite 
Tipo A, do Leite Tipo B, do Leite Tipo C, do Leite Pasteurizado e do Leite Cru Refrigerado e o Regulamento Técnico da Coleta de Leite Cru Refrigerado e seu transporte a Granel. Diário Oficial da União, Brasília, 18 set. 2002, Secção 3, p. 13. Disponível em: http://adcon.rn.gov.br/ACERVO/EMATER/DOC/DOC000000000001051.PDF. Acesso em: 16 abr. 2018.

CAMPOS, Mariana Magalhães. Pecuária leiteira de precisão: desafios e oportunidades. Embrapa Gado de Leite, 2013. Disponível em: http://www.repileite.com.br/forum/topics/pecu-ria-leiteira-de-precis-o-desafios-eoportunidades. Acesso em: 16 abr. 2018.

CARNEIRO, Rafael Luiz et al. Aspectos essenciais das baterias chumbo-ácido e princípios físico-químicos e termodinâmicos do seu funcionamento. Revista Virtual de Química, v. 9, n. 3, p. 889-911, 2017. Disponível em: http://dx.doi.org/10.21577/1984-6835.20170057. Acesso em: 18 abr. 2018.

CHAGAS, Marcos Wilson Pereira. Novas tecnologias para avaliação de baterias. 2007. 97 f. Dissertação (Mestrado Profissionalizante em Desenvolvimento de Tecnologia) - Instituto de Engenharia do Paraná, Institutos Lactec, Curitiba, 2007. Disponível em: http://totalinspe.dominiotemporario.com/doc/MarcosWilson.pdf. Acesso em: 18 abr. 2018.

CUNHA, Alessandro F. O que são sistemas embarcados? Revista Saber Eletrônica, v. 43, n. 414, p. 39-43, 2007. Disponível em:

http://files.comunidades.net/mutcom/ARTIGO_SIST_EMB.pdf. Acesso em: 19 abr. 2018.

DIAS, Kelvin Lopes; SADOK, Djamel Fauzi Hadj. Internet móvel: tecnologias, aplicações e QoS. In: SIMPÓSIO BRASILEIRO DE REDES DE COMPUTADORES, 19., 2001, Florianópolis. Anais... Florianópolis, 2001. Disponível em: http://www.cliqueapostilas.com.br/Apostilas/Download /internet-movel--tecnologias-aplicacoes-e-qos. Acesso em: 19 abr. 2018.

ERICKSON, Christine. A brief history of text messaging. 2012. Disponível em: http://mashable.com/2012/09/21/text-messaging-history/\#RkiBphObCZqh. Acesso em: 19 abr. 2018.

EVANS, Martin; NOBLE, Joshua; HOCHENBAUM, Jordan. Arduino em ação. São Paulo: Novatec Editora, 2013.

MCROBERTS, M. Arduino básico. São Paulo: Novatec, 2011.

NETTIGO. SIM800L GSM/GRPS module. 2018. Disponível em: https://nettigo.eu/products/sim8001-gsm-grps-module. Acesso em: 19 abr. 2018.

OKI, Nobuo; MANTOVANI, Suely Cunha Amaro. Microcontroladores. Ilha Solteira: Faculdade de Engenharia de Ilha Solteira, 2013. 18 p. Disponível em: 
http://www.feis.unesp.br/Home/departamentos/engenhariaeletrica/microcontroladores-_pic1.pdf. Acesso em: 19 abr. 2018.

OLIVEIRA, Arthur Filgueiras de. Modelagem, parametrização e otimização de baterias chumbo-ácido em aplicações ferroviárias via análise de big data. 2016.67 f. TCC (Graduação em Engenharia Elétrica) - Faculdade de Engenharia Elétrica, Universidade Federal de Juiz de Fora, Juiz de Fora, 2016. Disponível em: http://www.ufjf.br/eletrica_energia/files/2016/11/TCC_ARTHUR-OLIVEIRA-Final.pdf. Acesso em: 19 abr. 2018.

PEIXOTO, Thiago Moratori et al. Sistemas embarcados: explore sua criatividade construindo Hardware e Software. In: SIMPÓSIO MINEIRO DE COMPUTAÇÃO DA VII ESCOLA REGIONAL DE INFORMÁTICA DE MINAS GERAIS, 2012, Juiz de Fora. Anais... Juiz de Fora: 2012. Disponível em: http://www.lrc.ic.unicamp.br/ luciano/publications/smc12.pdf. Acesso em: 19 abr. 2018.

PENIDO, Édilus de Carvalho Castro; TRINDADE, Ronaldo Silva. Microcontroladores. Ouro Preto: IFMG, 2013. 80 p. Disponível em:

http://estudio01.proj.ufsm.br/cadernos/ifmg/tecnico_automacao_industrial/microcontroladores .pdf. Acesso em: 19 abr. 2018.

PEREIRA, Luiz Arthur Malta et al. Software Embarcado, o Crescimento e as Novas Tendências Deste Mercado. Revista de Ciências Exatas e Tecnologia, v. 6, n. 6, p. 85-94, 2015. Disponível em: http://pgsskroton.com.br/seer/index.php/rcext/article/view/2308/2208. Acesso em: 15 abr. 2018.

RECHE, Natalia Luiza Machado. Influência do armazenamento do leite em resfriador por expansão direta sobre a contagem de micro-organismos e estabilidade da caseína. 2013. 92 f. Dissertação (Mestrado em Ciência Animal) - Centro de Ciências Agroveterinárias, Universidade do Estado de Santa Catarina, Lages, 2013. Disponível em: http://www.cav.udesc.br/arquivos/id_submenu/756/dissertacao_natalia_reche.pdf. Acesso em: 15 abr. 2018.

SEGUEL, Júlio Igor López. Projeto de um sistema fotovoltaico autônomo de suprimento de energia usando técnica MPPT e controle digital. 2009. 222 f. Dissertação (Mestrado em Engenharia Elétrica) - Escola de Engenharia, Universidade Federal de Minas Gerais, Belo Horizonte, 2009. Disponível em: https://www.ppgee.ufmg.br/defesas/216M.PDF. Acesso em: 19 abr. 2018.

SIMCOM. SIM800L User Manual. 2005. Disponível em: https://fccid.io/UDV2013072402/Users-Manual/User-Manual-2062907.pdf. Acesso em: 17 abr. 2018.

STEIB, Cristian. GSM Sim800I Arduino Library. 2017. Disponível em: https://cristiansteib.github.io/Sim8001. Acesso em: 19 abr. 2018.

TEIXEIRA, Gabriel Ramos; CAMPOS, Gustavo Lobato. Circuito protótipo para indicação de falta de energia para sistema de armazenamento de leite em pequenas propriedades. In: 
CONFERÊNCIA DE ESTUDOS EM ENGENHARIA ELÉTRICA (CEEL), 15., 2017, Uberlândia. Anais... Uberlândia: UFU, 2017. Disponível em:

https://proceedings.science/ceel/trabalhos/circuito-prototipo-para-indicacao-de-falta-deenergia-para-sistema-de-armazenamento-de-leite-em. Acesso em: 19 abr. 2018.

TOLENTINO, Jamie. Why are people still using SMS in 2015? Future of Communications, Amsterdam, 2015. Disponível em: https://thenextweb.com/future-of-

communications/2015/02/16/people-still-using-sms-2015/\#.tnw_TUvVBuMy. Acesso em: 19 abr. 2018.

TORRES, Rodolpho de Almeida; OLIVEIRA, Vânia Maria; SOUZA, Guilherme Nunes de. Dicas de manejo de ordenha para obtenção de um leite de qualidade. In: TORRES, Rodolpho de Almeida et al. Tecnologias para melhoria da produção de leite da Zona da Mata Mineira. Juiz de Fora, 2001. Cap. 7. p. 55-62. Disponível em: https://docplayer.com.br/16372142-Dicas-de-manejo-de-ordenha-para-obtencao-de-um-leitede-qualidade-introducao-a-higiene-na-ordenha-capitulo-7.html. Acesso em: 14 abr. 2018.

UNICOBA. Manual Técnico UNIPOWER: Série UP: Bateria Chumbo-Ácida Selada Regulada por Válvula. [São Paulo, 2016]. Disponível em: https://www.robocore.net/upload/ManualTecnicoBateriaUnipower.pdf. Acesso em: 15 abr. 2018.

\section{DADOS DOS AUTORES}

\section{Gabriel Ramos Teixeira}

E-mail: gabrielramos.tx@gmail.com

Currículo Lattes: http://lattes.cnpq.br/4873796709909367

Graduado em Engenharia Elétrica pelo Instituto Federal de Educação, Ciência e Tecnologia de Minas Gerais (IFMG) Campus Formiga. Atuou como bolsista em projetos de pesquisa nas áreas de automação residencial e monitoramento de processos. Tem interesse nas áreas de Automação, Sistemas Embarcados, Eletrônica e Telecomunicações.

\section{Gustavo Lobato Campos}

E-mail: gustavo.lobato@ifmg.edu.br

Currículo Lattes: http://lattes.cnpq.br/9613750934178733

Doutorado em Engenharia Nuclear pela Universidade Federal de Minas Gerais (UFMG) na área de Ciência das Radiações. Mestrado em Engenharia Elétrica pela Pontifícia Universidade Católica de Minas Gerais (PUC Minas) na área de Compatibilidade Eletromagnética. Graduado em Engenharia Eletrônica e de Telecomunicação pela PUC Minas. Atua como professor (dedicação exclusiva) do Instituto Federal de Minas Gerais, IFMG Campus Formiga, na área de Eletrônica. 